Article

\title{
Remote Teaching of Building Information Modeling During the COVID-19 Pandemic: A Case Study
}

\author{
Conrad Boton 1 \\ Department of Construction Engineering, École de Technologie Supérieure, Montreal, QC H3C 1K3, Canada; \\ conrad.boton@etsmtl.ca
}

Received: 2 September 2020; Accepted: 15 October 2020; Published: 19 October 2020

\begin{abstract}
This article reports on a Building information modeling (BIM) distance learning experience in a pandemic context. Based on a description of the experience and a survey completed by the learners at the end of the course, the article presents and discusses various aspects of the training, including the overall satisfaction of the learners, their evaluation of the technical aspects and the practical work, as well as the proposals made to improve the course. The analysis shows that some elements of the teaching functioned well, while others were rated as being less satisfactory by the students. More specifically, the learners highlighted the need to find ways and means to improve the level of interaction, which is reduced by online education. The use of video clips as a support for practical work was recognized as being effective, but it seems useful also to resort to the use of collaborative platforms dedicated to the construction industry. A critical aspect is the remote access to computer labs with computers where the taught software is installed, as not all of the learners will always have the option of having it on their personal computers. Although the results of the experiment are difficult to generalize due to its particular context, they identify interesting avenues for improvement while paving the way to unique opportunities for the use of active pedagogy principles in BIM education.
\end{abstract}

Keywords: online education; distance learning; building information modeling; engineering education; COVID-19

\section{Introduction}

The confinement caused by the pandemic linked to the new coronavirus (Covid-19) in 2020 in most countries forced many universities to continue their education at a distance. In some cases, the change was made without much difficulty, with the courses having already been prepared to be able to be given online. However, in most cases, both the teachers and learners were taken by surprise, as the teachers found themselves having to rapidly adapt the content of their training to the demands of distance education. When the training relates to the teaching of holistic approaches, such as building information modeling (BIM), involving the learners' mastery of several dimensions (technological, organizational and procedural), the adaptation of the content must be accompanied a judicious choice of technological and educational tools.

Several research studies have been devoted to the impact of BIM on teaching practices in construction engineering [1,2], as well as on distance education [3]. This work generally emphasizes issues related to the establishment of coherent academic curricula [2,4] or technological challenges, and the success factors of distance education [5-7]. This work is mainly based on a teacher's perspective, and on feedback from the teacher's point of view. This results in a lack of knowledge and consideration of the perspective of the learners. However, understanding this perspective is crucial to the adaptation of the content of the BIM curricula and the related teaching strategies. Better still, the new reality imposed by the COVID-19 pandemic is forcing universities to react quickly to best meet the needs of 
their student clientele. The question therefore arises as to whether the responses provided are in phase with the needs of the learners, and how to measure the perception of these responses by the learners.

This article reports on a distance learning experience of BIM at an engineering university during the pandemic. The objective is to illustrate, in a neutral way, the difficulties and the opportunities offered by this unprecedented situation, adding to the perspective of the teacher the point of view of the learners. To this end, the article describes the background and the educational material developed, and is based on a survey completed by the students to present the learners' perception of the results of the teaching experience.

The remainder of the article is organized into four main sections. Section 2 presents a review of the literature, including a brief summary of the evolution of engineering education approaches, the impact of BIM on construction engineering education, and distance education in construction engineering and in the modeling of building data. Section 3 develops the context and the teaching device, allowing the reader to form a good understanding of the organization of the course, the teaching material, and the approach to the collection of feedback from the learners. Section 4 presents the results, with an emphasis on the overall evaluation of the course, an evaluation of its technical aspects, our evaluation of the practical work, and our proposals to improve the course. The final section discusses these results and concludes the article.

\section{Background}

\subsection{The Evolution of Teaching Approaches in Engineering}

Traditional approaches remain the types most widely used in engineering education, but several critiques of these approaches have emerged in recent decades. These have particularly emphasized the lack of alignment of these approaches with industry practices [8], the difficulty in supporting teamwork, and the difficulty of effectively transmitting the necessary communication skills, which are increasingly essential for graduates [9]. In response to these criticisms, new approaches have emerged, with learner-centered and 'what is learned' approaches. These approaches include project-based learning, problem-based instruction, and the flipped classroom.

Project-based learning can be defined as "a comprehensive approach to teaching and learning in the classroom, designed to engage learners in studying authentic problems" [10,11]. Problem-based learning is a variant of the project-based teaching that originated at McMaster University in Canada and is widely used in medical education [12], as well as in other fields [13,14]. Based on a set of problems serving as a common thread in the learning process [15], it can be particularly effective for learning in engineering [15]. However, this effectiveness requires a good definition of how the problem is presented to the learners, as well as sufficient time dedicated to working on it [16].

In the flipped classroom approach, instead of giving presentations inside the classroom and requiring that practice exercises and problem solving be performed outside of the classroom, "the events that traditionally take place inside the classroom now take place outside the classroom and vice versa" [17]. Practical exercises and problem solving are used inside the classroom time and video lectures are offered outside the classroom time [18]. The discussion offered by Mills and Treagust [8] suggests that the best approach to teaching engineering should be a good mix of traditional methods and active learning.

\subsection{The Impact of BIM on Construction Engineering Education}

The construction industry, which has long been considered resistant to change and resistant to technology, is a poorly performing industry compared to other industries, such as the aerospace and the automotive industries [19]. However, the last decades have seen considerable efforts invested into a digital transition, characterized by the greater adoption of information technologies. The building information modeling (BIM) approach occupies an important place in this digitization of the built 
environment [20], and the initiatives aimed at a greater digitization of the construction industry are increasingly grouped under the concept of Construction 4.0 [21,22].

The evolution of university engineering education is influenced by two main movements, one technological and the other ideological [18]. In the context of the advent of Construction 4.0 and BIM, universities must give special emphasis to the technological movement. This is mainly due to the appearance of new roles and responsibilities in construction projects [23] which require significant technological and technical skills associated with the use of building modeling and data management software [24]. In reality, these roles are quite varied and constantly changing, which does not facilitate their understanding in a sufficiently precise way to be able to adapt the teaching of them. One thing seems certain, however: the great variety in the roles of BIM specialists forces universities to find the right balance between knowledge related to technology, and knowledge related to organization and processes [1].

Boton et al. [2] proposed a discussion of issues related to the teaching of the BIM approach in university engineering education. Their work identifies seven groups of challenges, namely the skills to be acquired, the educational approach, the assessment methods, the technological environment, industrial partnerships, the implementation approach, and the timetable. They also suggested the idea that new teaching approaches, such as the flipped classroom, may be particularly effective for the teaching of building information modeling. However, the work does not explicitly address the issue of distance education.

\subsection{The Distance Learning of Building Information Modeling}

In 2016, Adamu and Thorpe [3], in their analysis of BIM teaching practices in universities, reviewed the BIM courses offered in Great Britain. The low number of BIM programs offered at the undergraduate level led them to the observation that BIM is offered mainly as a specialization for the purposes of "professional development and certification" [3]. In this context, distance education is popular in the programs identified. Indeed, this mode of teaching could prove to be "the best or the most preferred for AEC professionals who wish to improve in BIM in order to progress in their career" [3].

In the dedicated literature, the distance teaching of BIM has been addressed by several studies, some $[25,26]$ emphasizing the issues related to the teaching of the collaborative aspects of BIM. Others focus on the technological aspects of BIM [5], design processes [4], or the success factors [6,7] of distance BIM training. Still other works $[27,28]$ focus on the increasingly frequent use of open online training (MOOC) in order to generalize the dissemination of theories and concepts associated with BIM.

Holzer [29] recently presented a very interesting analysis of two online teaching experiences based on the principles of blended learning and the semi-inverted classroom. The author discusses ways to optimize learning outcomes while minimizing the effort of developing educational materials. Based on student feedback, several aspects of teaching were assessed. Holzer [29] concludes that the "semi-inverted classroom model offers clear advantages over classroom-only software training", especially when the teaching materials are designed to handle the repetitive aspects of the course, in a way that allows the group to focus on more complex issues requiring face-to-face interaction between teacher and learners. The study also highlights the difficulty for students to follow the courseware live, as the inherent complexity of design tools and BIM software makes that a complicated task. Finally, the study concludes on the importance of allowing learners to "browse through content after class at their own pace", so that it is easier to repeat the teacher's instructions.

\subsection{Research Gap}

As we can see, practices are changing in the industry, and BIM is a good illustration of this. Significant efforts have been made to adapt curricula and teaching approaches to this development. However, the COVID-19 pandemic has made it possible to realize how much effort is still required 
to meet the needs of learners in a sustainable and agile manner. While several resources have been developed and made available online by various industry players, including software developers, these resources are still far from being able to replace the university curricula that are generally more suited to the challenges of the local industry. These curricula therefore remain very important in the dissemination of BIM, even though the educational approaches used are not always the most appropriate. Advances in flipped classroom and project-based pedagogy are certainly commendable, but must be put to the service of a more global approach, the definition of which is based on a good understanding of empirical data from learners, so as to ensure no only a success but also a comparison between the approaches and sustainable solutions on an international scale.

On the other hand, as Holzer's study [29] shows, when looking at the perspective of the learners, it is interesting to note that a semi-inverted classroom approach can be particularly effective. However, the development of new and suitable teaching materials is crucial, and the complexity of BIM software makes it difficult to learn live online. The sustainable resolution of these challenges requires further studies to understand them in detail and to collect the students' point of view as to possible solutions to be considered.

Thus, the research questions of the present study can be summarized as follows: how do learners perceive the issues associated with online BIM learning? What solutions do they suggest in order to sustainably resolve them?

\section{Materials and Methods}

\subsection{Context}

The École de Technologie Supérieure (ÉTS) is a Canadian university institution with an applied engineering mission. The close links it maintains with industry allow it to match the content of the training offered to the real needs of the industry. Thus, the construction engineering department has a mission to train highly qualified personnel corresponding to the expectations of the construction market in Quebec.

Since 2017, ÉTS created a short program in building information modeling (BIM), comprised of six courses, including a seminar on construction management, a course on the use of information technologies in the construction industry, an introductory course in building information modeling (the subject of this article), a course in the management and monitoring of BIM projects, a course in construction planning (4D) and cost estimation (5D), and a course on energy efficiency in buildings based on BIM.

The experience reported in this article concerns the Introductory building information modeling course. This is the first regular course on the subject of BIM at the university level in Quebec. While this course is part of the BIM short program at ÉTS, students can also take it as part of the construction engineering master's program. Its objective is to introduce learners to the processes and the main software tools associated with BIM, and to teach them good practices in the production of multidisciplinary digital models. The course is based on a good balance between theoretical learning and modeling practice, and is largely given in a computer lab. It is available in an intensive mode, over three weekends (Fridays and Saturdays). The Fridays are dedicated to theoretical lessons, and the Saturday sessions are devoted to carrying out practical work within the framework of the student's session project.

The practical works are performed within teams of two to three students. In the first week, the practical work is carried out using Autodesk Revit software. The learners are led to create an architectural model of a building. The students have to create the architectural model of a building of which the plans, sections and facades are proposed to them. They must create the corresponding 3D model with all of the objects modeled with the family corresponding to their function, while respecting the prescribed dimensions. Learners must also create new families of objects and integrate them into the model. The proposed models must have a good structure in the project browser, in order to 
foster navigation and searching. They must also add appropriate elements of interior architecture. The learners have to extract two nomenclatures of quantities and generate examples of 2D project documentation directly from the model. Their work during the second week is to make the structural model of the same building, using Tekla Structures software. The creation of such a structural model has to respect a certain number of requirements, including the creation of the axis system, the respect of the geometry, the preparation of an analysis model, the modeling of the typical connections (end plate, shear, vertical bracing), and the force structure plan. Particular attention is paid to the exact modeling of the joints, to respecting the series of imposed brands, and to the correct location of the connections. For the practical work of the third week, they federate the two models using Navisworks Manage software, carry out multidisciplinary coordination, identify and correct clashes and other coordination errors, and issue recommendations to professionals.

\subsection{The Teaching Materials}

Specific teaching materials were developed in order to amplify the learning and to allow more time to be spent in the classroom on the practical matters of that are of interest to the students. The development of these teaching materials was inspired by flipped classroom practices. The learning mode of the flipped classroom consists of setting up a device to allow the students to learn the basic concepts by themselves, thereby optimizing class time for practical activities, specific problems proposed by the students, and exchanges of experience. These educational materials are summarized below:

- The preparation of a document entitled 'Introduction to BIM: Course notes for MGC0847', summarizing the essential content of the various traditional materials of the course. This document was developed to serve as a 'pocket book', giving students all the theoretical information necessary to understand the course.

- The production of 30 video capsules (using Camtasia software, TechSmith, Okemos, MI, USA) on the use of Autodesk Revit, Tekla Structures and Navisworks Manage software, for the realization of the practical work. The video capsules are an average of $3 \mathrm{~min}$ each. The subject and the title of each video are identified so as to cover the stages of the realization of the deliverables of the session project, and to allow the students to find them easily.

- The production of eight 10 minute videos, explaining the key theoretical concepts covered in the course. In each of these videos, a teacher is filmed as they explain a key, but complex concept of the course.

- The preparation of quizzes (on the Moodle platform) in order to assess the learning and skills acquired by the students. Two quizzes were scheduled: one each during the second and third weekends, in order to ensure that the students have fully assimilated the essential knowledge of the required readings. To achieve this, a database of 100 questions was developed, and the questions for each quiz were taken from this database.

In addition, in order to be able to carry out the practical work from home during the pandemic period linked to COVID-19, the students were invited to install the three studied software packages on their personal computers, with educational licenses accessible with their school credentials. The ÉTS also set up a system that allows learners to access the school's computer labs remotely. Thus, the students have full access to the necessary software if they prefer not to install it on their personal computers. In order to ensure equitable access to the laboratories, the school introduced some restrictions, limiting the access periods to class hours and in the evenings after 9 p.m. (until 7 a.m. the next morning). The sessions are limited to $4 \mathrm{~h}$, and users are automatically logged out after $4 \mathrm{~h}$ of use, after which they can reconnect to the system.

\subsection{Data Collection and Analysis}

In order to determine how the learners experienced the course, a completely anonymized questionnaire was prepared and posted online via the Limesurvey platform. The students were invited 
to complete the survey on the last Saturday of the course, just before the start of the labs with Autodesk Navisworks software (San Rafael, CA, USA). This timing was chosen because they had completed and submitted the first two labs (with Autodesk Revit and Tekla Structures), and the vast majority of the students were online for the start of the last practical work. One consequence of this choice is that the practical work with Navisworks could not be assessed.

The questionnaire was organized into four main parts. The first part identifies the respondent through their area of specialization, whether or not they are enrolled in the BIM program, and the number of courses in the program they had already taken before this course. The second part measures the learner's satisfaction with the course, with an emphasis on the presentation format, level of interaction, pace of presentation, small group work and teaching materials. This part also assesses the learner's satisfaction with the technical aspects, such as the use of the Zoom platform, the course's Moodle site, and the remote access to the school's computer labs. The students are also invited to give their opinion on how the online education could be improved.

The third part investigates the difficulties encountered, and the students' satisfaction with the proposed solutions. These difficulties include those relating to access to the course site, remote access to the computer labs, the use of the Zoom platform, the quality of audio reception, and the quality of the remote access to media. In the fourth part, the practical details of working with the Autodesk Revit and Tekla Structures software (San Rafael, CA, USA) are assessed as a whole, as well as for their content. This part also seeks feedback on the video support capsules and the supervision by the teachers.

The students were invited to complete the questionnaire completely anonymously. The responses received on the Limesurvey platform were therefore fully anonymized, with nothing allowing them to be linked to the respondents. A total of 45 responses were received out of the 47 students enrolled in the course: an encouragingly high level of participation. Although the platform provided basic data processing functionalities, we preferred to process the data with Microsoft Excel. All of the data was therefore exported to Microsoft Excel using the comma-separated values (CSV) file format. All of the graphs presented in the rest of the article were made with Microsoft Excel.

\section{Main Results}

\subsection{Overall Evaluation of the Course}

The students were asked to rate their level of satisfaction with the course, in particular with the presentation format, the level of interaction between the teacher and the learners, the pace of the presentation, the work in small groups, and the teaching materials (Figure 1). Here, interaction is referred to as the reciprocal reaction between a student and the teacher, including sequences of questions and answers, or assistance in solving a technical problem. 


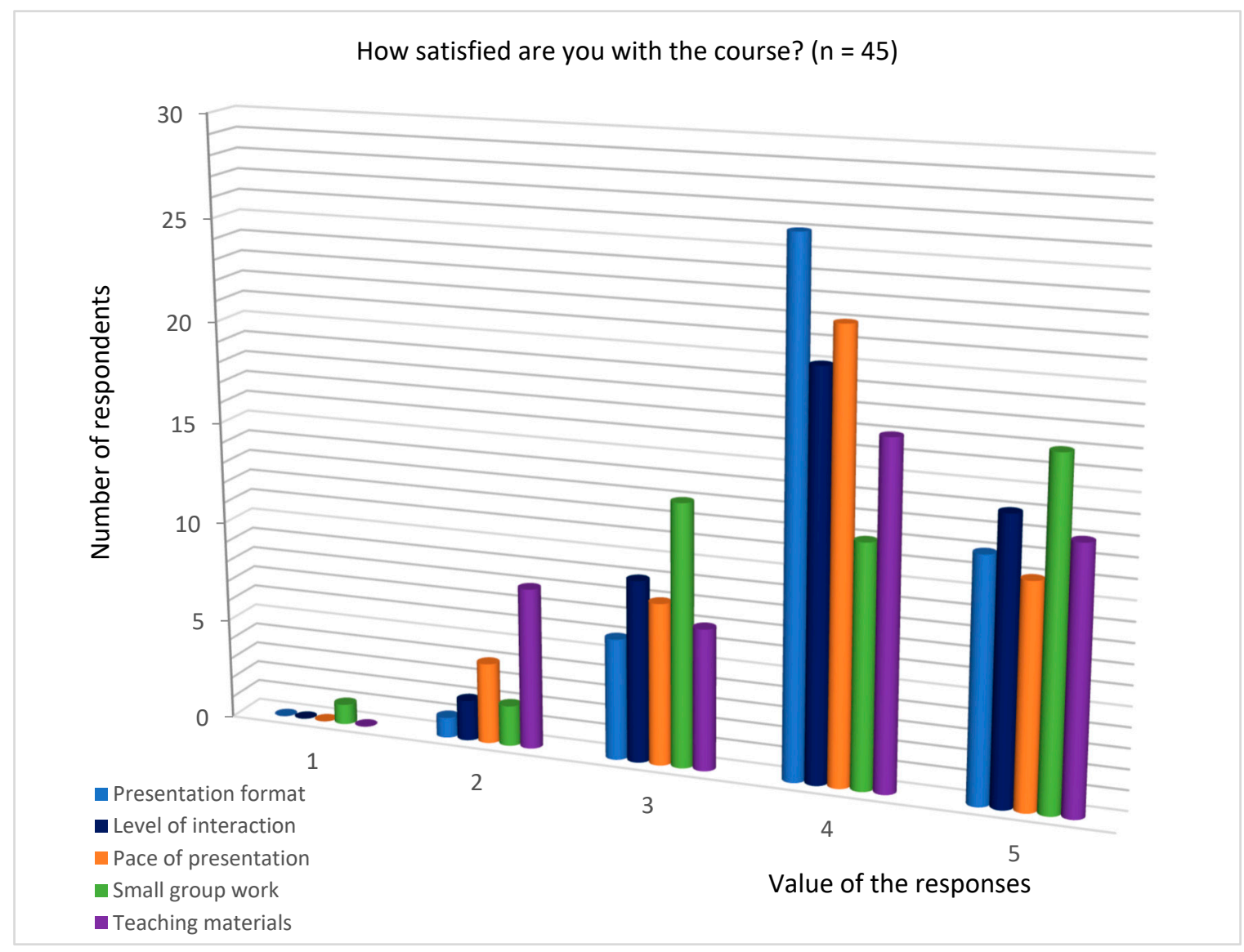

Figure 1. Degree of satisfaction with the course.

The vast majority of the learners gave a positive response to the presentation format, with 12 respondents being very satisfied, and 26 respondents being satisfied. Six respondents gave a score of 3 , and one respondent was less satisfied, with a score of 2 out of 5 . No respondent indicated that they were not at all satisfied.

Regarding the level of interaction, 14 respondents said that they were very satisfied, and 20 respondents said that they were satisfied. Nine respondents gave a score of 3 , and two respondents were less satisfied, with a score of 2 out of 5 . No respondent was not at all satisfied.

Regarding the pace of presentation, 11 respondents said that they were very satisfied, and 22 respondents indicated they were satisfied. Eight respondents gave a score of 3, and four respondents $(8.89 \%)$ were less satisfied, with a score of 2 out of 5 . No respondent said they were not at all satisfied.

Regarding the teaching material, 13 respondents said that they were very satisfied, and 17 respondents said that they were satisfied. Seven respondents gave a score of 3 , and eight respondents were less satisfied, with a score of 2 out of 5 . No respondent was not at all satisfied.

\subsection{Evaluation of the Technical Aspects}

The second part also assessed the students' satisfaction with the technical aspects of the course (Figure 2). The vast majority of the learners gave a positive response regarding the use of the Zoom videoconferencing platform, with 24 respondents being very satisfied, and 14 respondents being satisfied. Six respondents gave a score of 3, and one respondent was less satisfied, with a score of 2 out of 5. No respondent was not at all satisfied. 


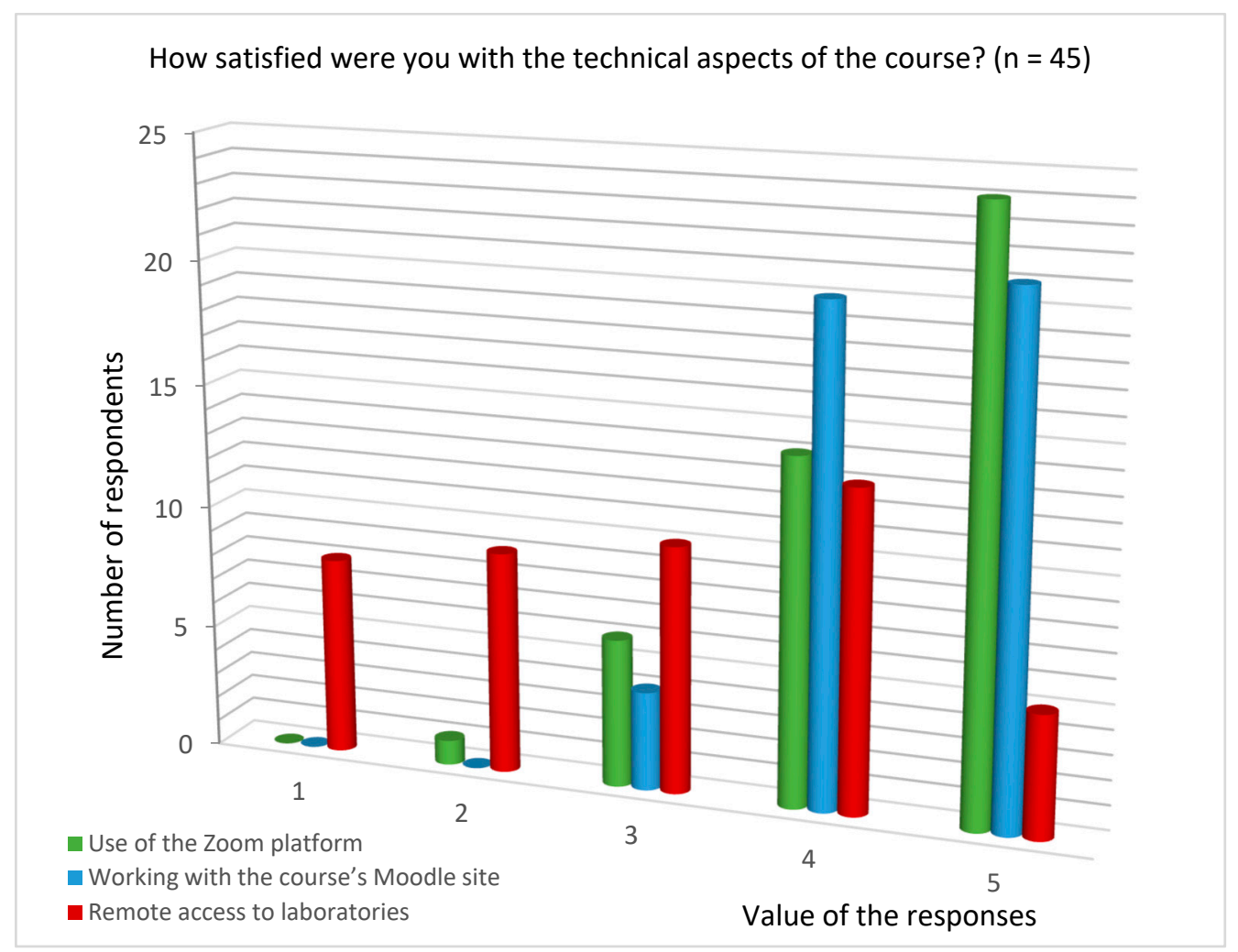

Figure 2. Level of satisfaction with the technical aspects of the course.

The course's Moodle site was rated positively by the vast majority of the learners, with 21 respondents being very satisfied, and 20 respondents being satisfied. Four respondents gave a score of 3 , and no respondent gave a score below 3 .

The remote access to the school's computer labs for practical work was rated much more severely by the learners, with only five respondents being very satisfied, and 13 respondents being satisfied. Ten respondents gave a score of 3, while 17 respondents gave a score below 3 .

The students were asked if they had encountered any technical difficulties during the course. Surprisingly, 21 respondents-representing a proportion of $44.68 \%$ of the sample-said that they had not encountered any. In order to verify this response, the learners were also asked to assess the difficulties encountered concerning their access to the course site, the remote access to the computer labs, the use of the Zoom platform, the quality of the audio reception, and the quality of the remote access to the course materials (Figure 3). 


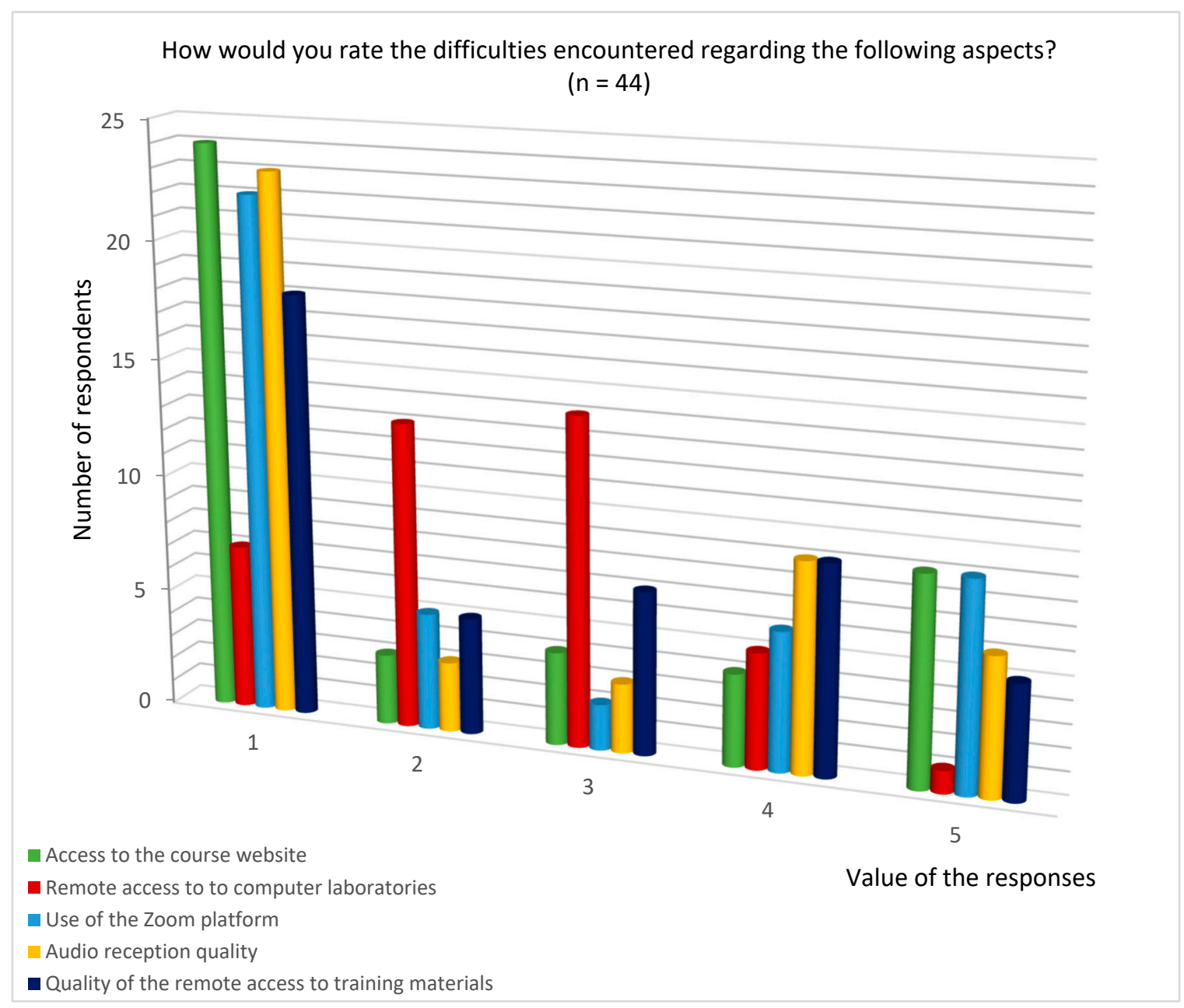

Figure 3. Difficulties encountered during the course.

Regarding the difficulties encountered in accessing the course site, nine respondents considered them to be critical, and four respondents found them to be very important. Four other respondents gave a median score of 3 . Three respondents had minor difficulties, while 24 respondents said they had no difficulty in accessing the course site.

Regarding the difficulties encountered in the remote access to the school's computer labs, five respondents considered them to be critical, and five other respondents found them to be very significant. Fourteen respondents gave a median score of 3 . Thirteen respondents had minor difficulties, while seven respondents said they had no difficulty remotely accessing the school's computer labs for practical work.

Regarding the difficulties encountered in using the Zoom platform, nine respondents considered them to be critical, and six respondents found them to be very significant. Three respondents gave a median score of 3 . Three other respondents had minor difficulties, while 23 respondents said they had no difficulty using the Zoom platform to follow the courses.

Regarding the difficulties encountered with the quality of the audio reception, six respondents considered them to be critical, and nine respondents found them to be very significant. Two respondents gave a median score of 3 . Five respondents had minor difficulties, while 22 respondents said they had no difficulty with the quality of the audio reception during the class sessions.

Regarding the difficulties related to the quality of the remote access to media, five respondents considered them to be critical, and nine respondents found them to be very significant. Seven respondents gave a median score of 3 . Five respondents had minor difficulties, while 18 respondents said they had no difficulty with the quality of the remote access to the materials. 
The learners were asked to rate the support that they received from their teachers or from the school's technical service in order to address the difficulties that they encountered (Figure 4).

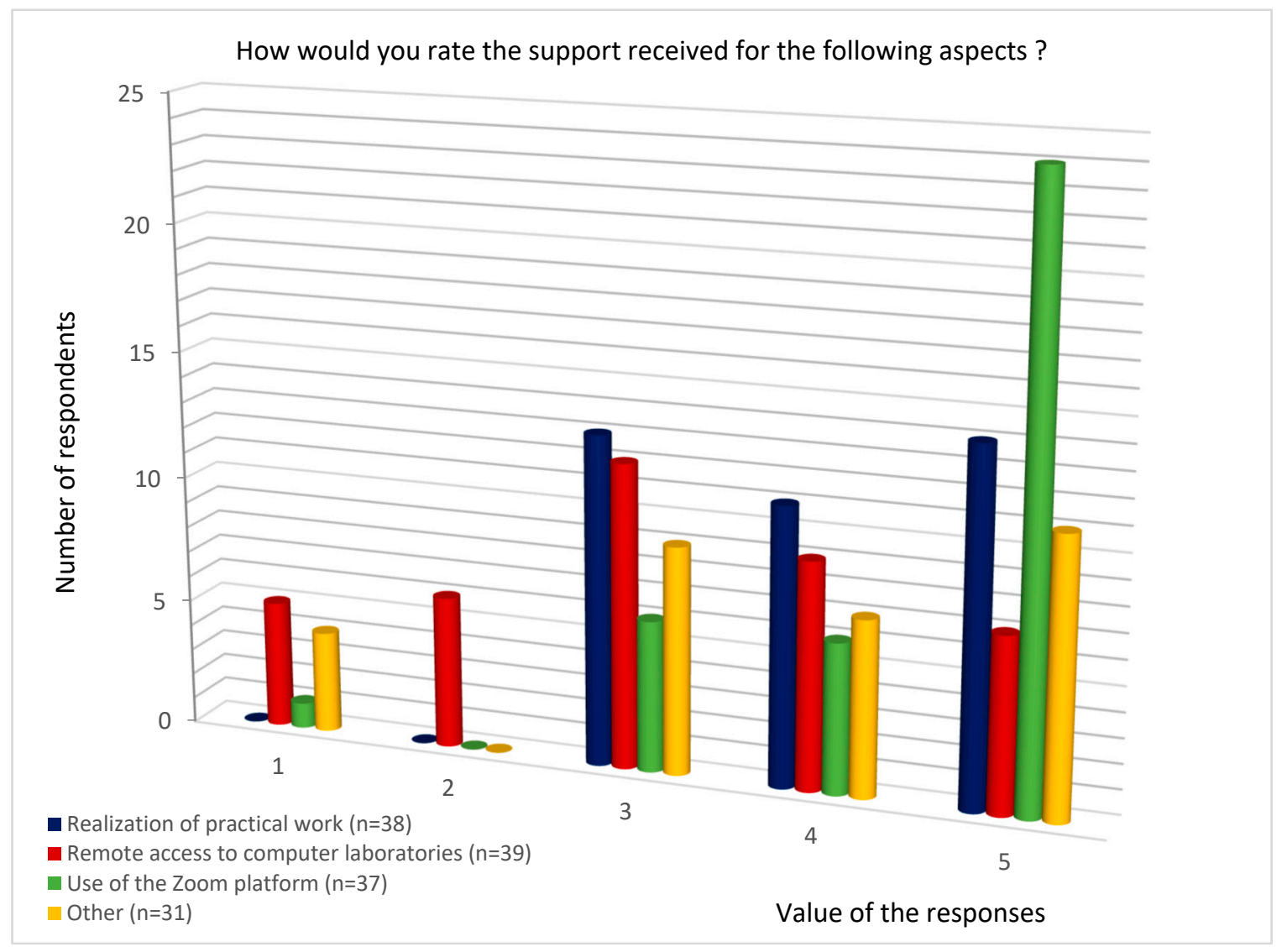

Figure 4. Support received during the course.

The support received as part of the practical work was assessed positively by the vast majority of the learners, with 14 respondents being very satisfied and 11 respondents being satisfied. Thirteen respondents gave a score of 3 , and no respondent gave a score lower than 3 .

Regarding the support received in the context of the remote access to the computer laboratories, it was judged to be very satisfactory by seven respondents, and satisfactory by nine respondents. Twelve respondents gave a score of 3 , while six respondents were unsatisfied, and five respondents were not at all satisfied.

The support received for using the Zoom platform was viewed positively by the vast majority, with 24 respondents being very satisfied, and six respondents being satisfied. Six other respondents gave a score of 3 , and one respondent was not at all satisfied.

Regarding the support that they received to resolve other technical difficulties, it was judged to be very satisfactory by 11 respondents, and satisfactory by seven respondents. Nine respondents gave a score of 3, while four respondents said that they were not at all satisfied.

\subsection{Evaluation of the Practical Lab Work}

The degree of student satisfaction with the practical work was assessed overall, as well as in terms of the content, the support videos and the teacher guidance. These were divided into student evaluations of the lab work with Autodesk Revit (Figure 5) and their work with Tekla Structures (Figure 6). 


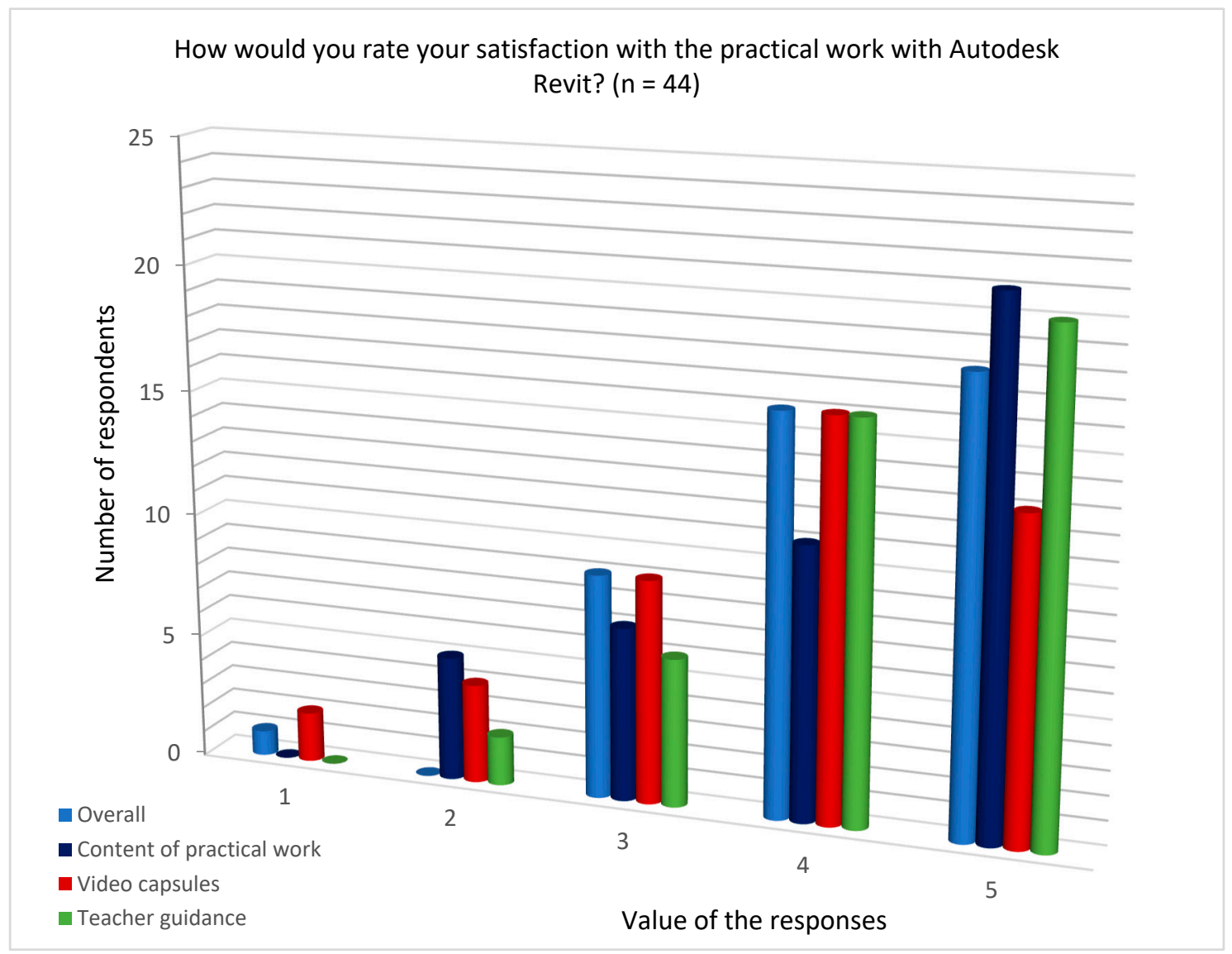

Figure 5. Satisfaction with lab work with Autodesk Revit.

Overall, the practical work with Autodesk Revit software was rated very satisfactory by 18 respondents, and satisfactory by 16 respondents. Nine respondents gave a score of 3 , while one respondent was not at all satisfied.

The contents of the practical work with Autodesk Revit software were rated very satisfactory by 21 respondents, and satisfactory by 11 respondents. Seven respondents gave a score of 3, while five respondents were not satisfied.

As for the video capsules for carrying out practical work with Autodesk Revit software, they were rated very satisfactory by 13 respondents, and satisfactory by 16 respondents. Nine respondents gave a score of 3, while four respondents were unsatisfied, and two respondents were not at all satisfied.

Regarding the teachers' supervision/guidance during the practical work with Autodesk Revit software, 20 respondents were very satisfied, and 16 respondents were satisfied. Six respondents gave a score of 3 , while two respondents were not satisfied.

Overall, the practical work with Tekla Structures software (Figure 6) was rated as being very satisfactory by nine respondents, and satisfactory by nine other respondents. Fourteen respondents gave a score of 3 , while 8 respondents were unsatisfied, and four respondents were not at all satisfied.

The contents of the practical work with the Tekla Structures software were rated very satisfactory by seven respondents and satisfactory by 14 respondents. Seven respondents gave a score of 3, while 12 respondents were unsatisfied, and four respondents were not at all satisfied.

The video support capsules recorded to address the issues involved in using the Tekla Structures software for practical work were judged to be very satisfactory by four respondents, and satisfactory by 13 respondents. Eight respondents gave a score of 3, while nine respondents were unsatisfied, and 10 respondents were not at all satisfied. 
Regarding the teachers' supervision in the practical work with the Tekla Structures software, 13 respondents were very satisfied, and 15 respondents were satisfied. Seven respondents gave a score of 3 , while 8 respondents were unsatisfied, and one respondent was not at all satisfied.

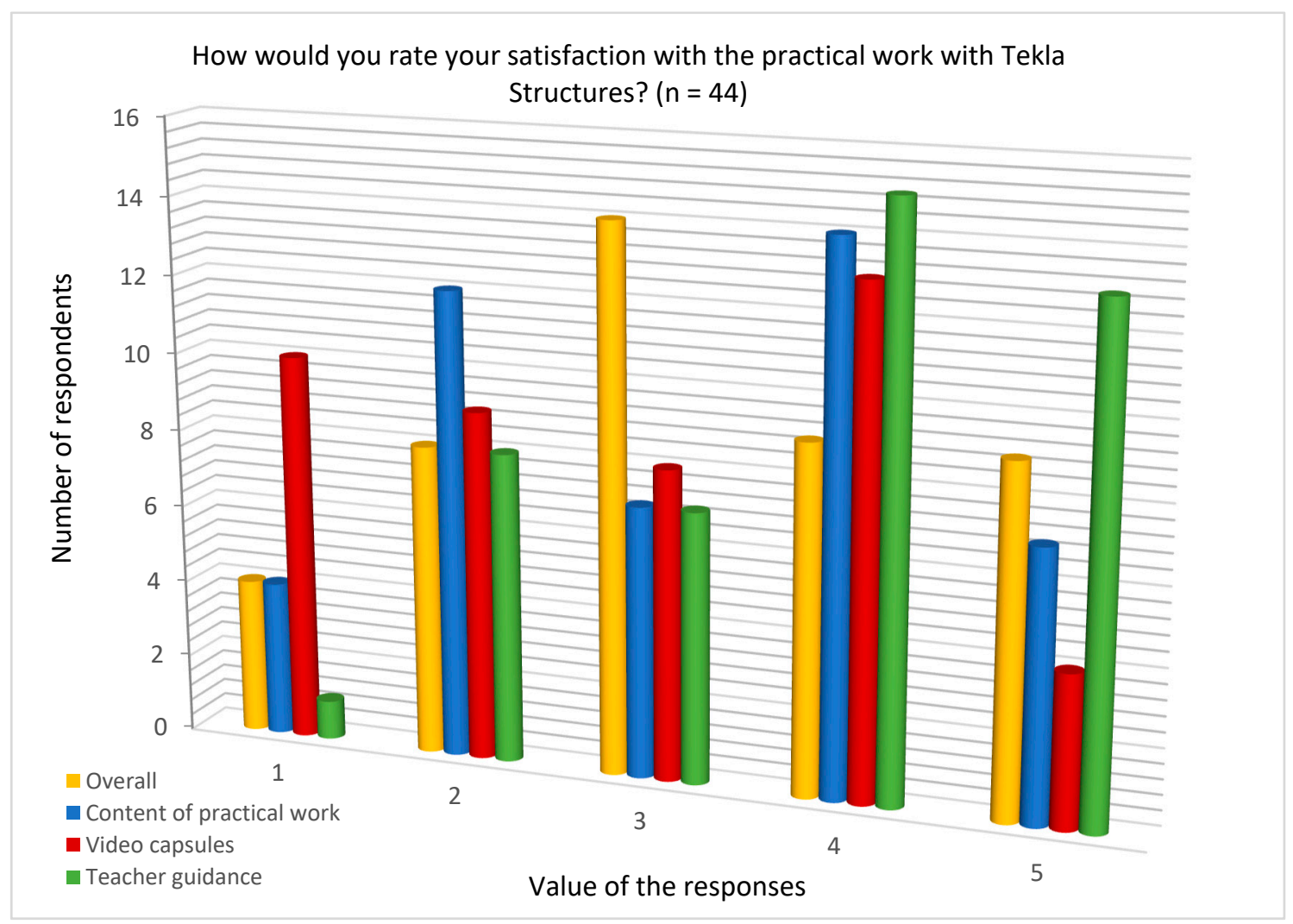

Figure 6. Satisfaction with lab work with Tekla Structures.

\subsection{Proposals to Improve the Course}

All of the class participants were asked to answer the following open-ended question: "How do you think the online teaching of this course could be improved?"

Overall, the vast majority of students provided positive feedback. "In general, I really enjoyed the course," said one respondent. There is "no need because it's great. Thank you very much, we took a lot of things," said another respondent. For another learner, "the online education went very well. It made me feel more at ease by setting up an interactive platform where we were all equal in terms of interaction compared to a traditional teaching format where the teacher is in front of the students". Another respondent emphasized the proper use of online tools: "I think the way the course is delivered has used the remote tools that are available very well, especially for the theoretical material. 10/10". The course's theory seems to have received a favorable response from the students as well: "The theory of this course has been very interesting and I recommend this course to students who wish to learn a little more about BIM" declared one student.

However, other statements better summarized the fact that several elements should be improved. "The online teaching went very well, with the exception of the accessibility to the laboratories, which being very limited, caused many complications for the delivery of the practical work (particularly the one on the Tekla software)", summarized one respondent. "I think there is a good balance between the duration and the technical aspects of the course. However, I think that the materials for each practical work project should be tied together to avoid contradictions or ambiguities". 
In the remainder of this section, the suggested improvements are organized into three main categories: sessions, tools and online issues; labs and team activities; and the remote access to computer labs.

\subsubsection{Online Sessions and Tools}

"The course requires a lot of practice and interaction. Done online this interaction is reduced". This commentary introduces the main issues of online sessions quite well. The intensive online sessions were rated as being difficult by the respondents. "It's hard to stay focused in front of a computer screen during the whole session, especially after long workdays during the week," said one respondent, highlighting the fact that the target audience for the course is composed of working people. It would therefore be useful to "reduce the number of hours of the lessons, after [a] certain time you lose concentration", according to another respondent. Along the same lines, "it is better not to exceed 5 hours online," said another student.

"We can improve the online teaching of this course," said one student. In order to achieve this, one learner suggested "reducing the theoretical part" of the course, on the understanding that "it is very difficult to follow on a computer screen for $7 \mathrm{~h}$ in a row". Another way to deal with the problem would be to "devote half a day to theory and the other half day to practice", because there is "too much material on Friday". It is mostly about "finding a way to better interact with students like the exercises you do in groups of 3 during class", according to one respondent.

Another suggestion is that "the use of Moodle could be improved by creating groups on Moodle to submit work. This way all team members will have access to the work repository and the responsibility to ensure that the work is submitted and that the good work is submitted".

\subsubsection{Practical and Team Work}

"The videos for the labs are great, except for the small differences depending on the version, but they are very well explained and are very appreciated", according to one learner. But doing the practical work remotely is "very complicated, especially with the quality of the videos," said one learner, who "suggests adding sound to the videos". It should be noted that, since the video capsules relating to practical work can be used in the classroom, sound descriptions were not added, as written instructions were deemed to be effective. Keeping them silent was deliberate, in order to prevent any noise from playing, thus keeping them from causing a nuisance during the classroom practice.

It was especially the part of the practical work carried out with the Tekla Structures software that crystallized the most suggestions for improvement. "Tekla training requires more organization in learning", said one respondent. "I found the Tekla lab to be very long and access to the labs difficult, [which] made the job more complex", confirmed another student. "The videos could also be modified to avoid redundancies and reduce their length", he suggests, as an avenue for improvement. "If the questions and answers of the other students during the group work time could also be broadcast, that would help a lot. I think this is an aspect that I missed a lot during the labs that I really benefited from when I was learning software in other courses", added yet another learner.

In order to improve the practical work, some students suggested resorting to the use of collaborative platforms. Thus, it was proposed "to improve the collaborative work and provide a platform for the members of each team to work at the same time". Another comment offered the same idea, "to offer a platform where you work on a single remote model instead of working in silos", which is well aligned with the principles of BIM.

\subsubsection{Remote Access to Computer Labs}

The difficulties of the remote access to the computer labs were pointed out by several students. The respondents' comments provide a better understanding of these difficulties, as well as some suggested solutions. "It was difficult to connect remotely in the laboratories outside of class hours", said a student. "Access to the laboratory that is too restricted [is] incompatible with the work," said another. 
The solution would be to "review remote access to laboratories in relation to the hours of access", suggested a respondent. "I would recommend more flexibility in the laboratory hours because it is not easy to work only from 9 in the evening to the morning knowing that I work during the day", specified another student. "It would be better to have access to the school lab during the day as well", said another respondent. In the same vein, one respondent believes that "we need to have access to the computer lab throughout the week so that we can follow our deliverable linked to the course".

\section{Discussion and Conclusions}

This article presented a distance education experience in building information modeling (BIM) during a pandemic. The aim was to evaluate the way in which learners perceive the issues associated with online BIM learning, and what solutions they suggest to sustainably resolve them. The results show that, from the perspective of the students, some aspects of the teaching worked well, while others were rated as being less satisfactory. The use of video capsules to support the practical work seemed to be well appreciated by the students, but the choice of the content of these videos was important for effective learning. Thus, the video capsules produced for the practical work with Autodesk Revit were particularly effective, unlike the support capsules for the practical work with Tekla Structures, even though all of the capsules were produced at the same time, following the same principles. It also seems necessary to provide for the use of a collaborative BIM platform that would facilitate the collaboration of students in the context of practical work. Effective remote access for the carrying out of the practical work emerged as an important point to consider. Despite the fact that the students were encouraged to install the software for free on their home computers, most preferred to use the school's computer labs remotely. This can be explained by various reasons, including the fact that said software is often greedy in terms of the resources required to make it work well, and the fact that using the laboratories allowed students of the same group to work on the same versions of these software packages, which are generally not backward-compatible.

The study tended to confirm the conclusions of Holzer [29] regarding the need for adapted teaching materials, and the difficulty for learners to follow the courseware live. An important point of precision highlighted by our study, and which needs to be outlined, is related the duration of the online sessions. The experience shows that it is important to avoid excessively long sessions, despite the fact that short breaks of about $15 \mathrm{~min}$ and a long break of one hour were planned. After a few hours, the learners seem to be unable to maintain focus and motivation. Some students suggested increasing the number of small group work modules. Others suggested giving more readings to complete at home. However, contrary to the initial expectations of the teachers, the students were in general satisfied with the teaching, in particular with the theoretical part of the course. The pandemic context of COVID-19 appears to have had a positive effect on the ability of students to be resilient and to assimilate theoretical content, despite the difficulties. Despite that, the balance between theory and practice seems to be crucial, with practice allowing learners to 'put their finger' on the theoretical concepts covered. The small group discussions, around open-ended questions relating to each important theoretical concept, also seemed effective in enabling the students to assimilate the essentials.

It is difficult to generalize these conclusions due to the fact that the analysis was made only of a single specific course, in a particular context. However, it offers a unique opportunity formulate some hypotheses about how to incorporate the learner's perspective to improve the course, and to better use the principles of active pedagogy for teaching holistic approaches like BIM. Additional studies with different contexts are necessary in the future in order to validate these hypotheses. Regarding the course analyzed in the study, it is already planned to take into account the results of the study, and to improve the teaching approach and materials in order to better respond to the new normality imposed by the COVID-19 pandemic.

In a global context of digital transition in the construction industry, reinforced by the COVID-19 pandemic, it is becoming more and more necessary for universities to use distance education in several industries. Although the results of this study are based on experience from the construction industry, they allow us to hypothesize that the distance teaching of other technological approaches similar to 
BIM could benefit from the conclusions of the study in other industrial fields where similar issues are observed. We can think, for example, of the distance teaching of Product Lifecycle Management (PLM) in the manufacturing industry, which is often compared to BIM because of the multiple similarities between the two approaches $[30,31]$. In addition, the academic constraints and the educational context—as summarized by Maranzana et al. [32] for PLM education—seem very similar to the issues identified in BIM education in construction [2]. Kakehi et al. [33] demonstrated the importance of using practical teaching methods based on case studies in the distance learning environment of PLM. In this context, one could hypothesize that some of the findings of the present study could be applied to distance education in PLM. However, this hypothesis should be verified by further studies. Future works should also compare the results of this research with other case studies in order to assess the extent to which they are generalizable.

\section{Data Availability Statement}

The data used to support the findings of this study are available from the corresponding author upon request.

Funding: This research was funded by the Institutional Support Program for Research and Teaching (PSIRE) of École de Technologie Supérieure.

Acknowledgments: The author thanks the Techno-pedagogical Support Office of the Dean of Studies of École de Technologie Supérieure for the support received during the teaching experience.

Conflicts of Interest: The authors declare no conflict of interest. The funders had no role in the design of the study; in the collection, analyses, or interpretation of data; in the writing of the manuscript, or in the decision to publish the results.

\section{References}

1. Boton, C.; Forgues, D.; Halin, G. Les enjeux liés à l'intégration de l'approche BIM de modélisation des données du bâtiment à l'enseignement universitaire: Cas d'une école d'ingénierie. Rev. Int. Technol. Pédagogie Univ. 2017, 14, 5-23. [CrossRef]

2. Boton, C.; Forgues, D.; Halin, G. A framework for Building Information Modeling implementation in engineering education. Can. J. Civ. Eng. 2018, 45. [CrossRef]

3. Adamu, Z.A.; Thorpe, T. How universities are teaching bim: A review and case study from the UK. J. Inf. Technol. Constr. 2016, 21, 119-139.

4. Tsai, M.H.; Chen, K.L.; Chang, Y.L. Development of a project-based online course for BIM learning. Sustainability 2019, 11, 5772. [CrossRef]

5. Mavroudi, A.; Hadzilacos, T. Learning needs analysis of collaborative e-classes in semi-formal settings: The REVIT example. Int. Rev. Res. Open Distrib. Learn. 2013, 14, 211-239. [CrossRef]

6. Wu, P.; Low, S.P.; Liu, J.Y.; Pienaar, J.; Xia, B. Critical success factors in distance learning construction programs at Central Queensland University: Students' perspective. J. Prof. Issues Eng. Educ. Pract. 2015, 141, 1-9. [CrossRef]

7. Wu, P.; Pienaar, J.; O’Brien, D.; Feng, Y. Delivering construction education programs through the distance mode: Case study in Australia. J. Prof. Issues Eng. Educ. Pract. 2013, 139, 325-333. [CrossRef]

8. Mills, J.E.; Treagust, D.F. Engineering education-Is Problem-Based or Project-Based Learning the Answer? Australas. J. Eng. Educ. 2003, 3, 2-16.

9. Char, S.V.; Collier, C.A. Chalk and Talk Versus Classroom Flipping: Results of a Case Study. J. Res. Method Educ. 2015, 5, 24-28.

10. Blumenfeld, P.; Soloway, E.; Marx, R.; Krajcik, J; Guzdial, M.; Palincsar, A. Motivating Project-Based Learning: Sustaining the Doing, Supporting the Learning. Educ. Psychol. 1991, 26, 369-398.

11. Heitmann, G. Project-oriented study and project-organized curricula: A brief review of intentions and solutions. Eur. J. Eng. Educ. 1996, 21, 121-131. [CrossRef]

12. Kilroy, D.A. Problem based learning. Emerg. Med. J. 2003, 21, 411-413. [CrossRef]

13. Chen, C.M.; Kuo, C.H. An optimized group formation scheme to promote collaborative problem-based learning. Comput. Educ. 2019, 133, 94-115. [CrossRef] 
14. Servant-Miklos, V.F.C.; Norman, G.R.; Schmidt, H.G. A Short Intellectual History of Problem-Based Learning. In The Wiley Handbook of Problem-Based Learning; Moallem, M., Hung, W., Dabbagh, N., Eds.; John Wiley \& Sons: Medford, MA, USA, 2019; pp. 3-24.

15. Perrenet, J.C.; Bouhuijs, P.A.J.; Smits, J.G.M.M. The Suitability of Problem-based Learning for Engineering Education: Theory and practice. Teach. High. Educ. 2000, 5, 345-358. [CrossRef]

16. Graaff, E.D. The Transformation Process from a Traditional Curriculum to Problem-Based and Project-Based Learning. In Proceedings of the 41st Conference of the International-Group for the European Society for Engineering Education, Leuven, Belgium, 16-20 September 2013; pp. 1-8.

17. Lage, M.J.; Platt, G.J.; Treglia, M. Inverting the Classroom: A Gateway to Creating an Inclusive Learning Environment. J. Econ. Educ. 2000, 31, 30-43. [CrossRef]

18. Bishop, J.L.; Verleger, M. The Flipped Classroom: A Survey of the Research. In Proceedings of the 2013 ASEE Annual Conference \& Exposition, Atlanta, GA, USA, 23-26 June 2013; pp. 1-18.

19. Green, S.D.; Fernie, S.; Weller, S. Making sense of supply chain management: A comparative study of aerospace and construction. Constr. Manag. Econ. 2005, 23, 579-593. [CrossRef]

20. Sacks, R.; Eastman, C.; Ghang, L.; Teicholz, P. BIM Handbook: A Guide to Building Information Modeling for Owners, Designers, Engineers, Contractors, and Facility Managers, 3rd ed.; Wiley: Hoboken, NJ, USA, 2018.

21. Boton, C.; Forgues, D. Construction 4.0: The Next Revolution in the Construction Industry. Available online: https://www.canbim.com/articles/construction-4-0 (accessed on 19 October 2020).

22. Boton, C.; Rivest, L.; Ghnaya, O.; Chouchen, M. What is at the Root of Construction 4.0: A Systematic Review of the Recent Research Effort. Arch. Comput. Methods Eng. 2020. [CrossRef]

23. Boton, C.; Forgues, D. Practices and Processes in BIM Projects: An Exploratory Case Study. Adv. Civ. Eng. 2018, 2018, 1-12. [CrossRef]

24. Barison, M.B.; Santos, E.T. An overview of BIM specialists. In Proceedings of the International Conference on Computing in Civil Engineering; Tizani, W., Ed.; Springer: Cham, Switzerland, 2010.

25. Becerik-Gerber, B.; Ku, K.; Jazizadeh, F. BIM-enabled virtual and collaborative construction engineering and management. J. Prof. Issues Eng. Educ. Pract. 2012, 138, 234-245. [CrossRef]

26. Mathews, M. BIM collaboration in student architectural technologist learning. J. Eng. Des. Technol. 2013, 11, 190-206.

27. Smith, P. Project cost management with 5D BIM. Procedia Soc. Behav. Sci. 2016, 226, 193-200. [CrossRef]

28. Ayub, E.; Wei, G.W.; Yue, W.S. Exploring factors affecting learners' acceptance of MOOCs based on kirkpatrick's model. In Proceedings of the 8th International Conference on E-Education, E-Business, E-Management and E-Learning-IC4E, Kuala Lumpur, Malaysia, 5-7 January 2017; pp. 34-39.

29. Holzer, D. Teaching computational design and BIM in the age of (semi)flipped classrooms. In Proceedings of the 24th CAADRIA Conference, Wellington, New Zealand, 15-18 April 2019; pp. 715-724.

30. Boton, C.; Rivest, L.; Forgues, D.; Jupp, J. Comparing PLM and BIM from the Product Structure Standpoint; Springer: Cham, Switzerland, 2016; Volume 492.

31. Boton, C.; Rivest, L.; Forgues, D.; Jupp, J.R. Comparison of Shipbuilding and Construction Industries from the Product Structure Standpoint. Int. J. Prod. Lifecycle Manag. 2018, 11, 191-220. [CrossRef]

32. Maranzana, N.; Segonds, F.; Buisine, S. Collaborative design tools in engineering education: Insight to choose the appropriate PLM software. Int. J. Mech. Eng. Educ. 2020, 48, 162-177. [CrossRef]

33. Kakehi, M.; Yamada, T.; Watanabe, I. PLM education in production design and engineering by e-Learning. Int. J. Prod. Econ. 2009, 122, 479-484. [CrossRef]

Publisher's Note: MDPI stays neutral with regard to jurisdictional claims in published maps and institutional affiliations.

(C) 2020 by the author. Licensee MDPI, Basel, Switzerland. This article is an open access article distributed under the terms and conditions of the Creative Commons Attribution (CC BY) license (http://creativecommons.org/licenses/by/4.0/). 